\title{
EDUCATIONAL POTENTIAL OF CHINESE UNIVERSITIES FOR THE IMPLEMENTATION OF CIRCULAR ECONOMY MODEL
}

\section{Dongxu Qu ${ }^{1}$ \\ Tetiana Shevchenko ${ }^{2}$}

DOI: https://doi.org/10.30525/978-9934-588-15-0-44

Abstract. The successful implementation of circular economy (CE) model needs the understanding and support of the whole public on the $\mathrm{CE}$ concept and knowledge, and then turns it into CE practice in the daily life. In order to enable the public to participate in $\mathrm{CE}$ activities, all sectors of society are actively exploring effective CE education. Colleges and universities are one of the direct driving forces in the implementation of CE model. Universities circular economy education (UCEE) is a novel concept, which refers to a kind of lifelong education with exerting the all the educational assets and influence of colleges and universities to radiate education to the whole society by taking college student education as the core, aiming at realizing the two primary targets of cultivating high-level professional talents of $\mathrm{CE}$ and enhancing the $\mathrm{CE}$ awareness of the whole public. However, there are many barriers in developing UCEE in reality, for example, there is insufficient policy support for CE practice in colleges and universities, general education of CE needs to be strengthened, professional development related $\mathrm{CE}$ is relatively lagging behind, curriculum setting of relevant professional courses of CE needs to be improved, and educational radiation of $\mathrm{CE}$ for the whole society is not enough. The existing research on $\mathrm{CE}$ education focused on improving the way of teaching, discipline construction and curriculum reform. However, there is little research on the role of the staff engaged in logistics service fields other than full-time teachers in implementing the education of sustainable development outside the curriculum and the systematic research on how to exert the educational

\footnotetext{
${ }^{1}$ Postgraduate Student, Sumy National Agrarian University, Ukraine Henan Institute of Science and Technology, China

${ }^{2}$ Associate Professor,

Sumy National Agrarian University, Ukraine
} 
potential of CE in colleges and universities is still insufficient. To bridge this gap, this study puts forward that college and university should pay more attention to the UCEE from top to bottom, strengthen the CE practice in campus with policy support, further enhance the general education for college students, perfect CE professional specialized talents training system according to the need of society, strengthen the cooperation with surrounding communities to popularization of CE education to the public. These strategies have strong applicability to improve the UCEE and can be used for reference by other Chinese universities.

\section{Introduction}

As an alternative to the traditional consumptive linear model, CE model is an economy model with high and new technology industry as the forerunner. By developing the technology of economical utilization and efficient recycling of natural resources, the implementation of $\mathrm{CE}$ is provided with possibility $[1$, p. 132]. The emergence of this possibility and whether this possibility can be turned into reality mainly depends on CE education. Meanwhile, in the way of an economy model developed in a knowledge-based society, CE model need the understanding, support and cooperation of the whole society, that is, the $\mathrm{CE}$ implementation needs carrying on the $\mathrm{CE}$ education for all citizens [2, p. 19]. Therefore, $\mathrm{CE}$ education is an important guarantee to put $\mathrm{CE}$ model into practice. However, the current level of $\mathrm{CE}$ education still cannot meet the needs of implementing CE model in China, and there are still limitations in the public's understanding and awareness of CE.

\section{Materials and methods}

In recent years, all sectors of society are actively exploring effective ways of CE education. At the government level, the Chinese National Development and Reform Commission and other four departments jointly issued "Notice on the Regulations on the Declaration and Management of the National CE Education Demonstration Base", focusing on building a high-quality CE education demonstration base as a platform to promote the CE concept to the public, and through the way of "replace subsidies with awards", using the CE development special funds to support the national CE education demonstration base [3, p. 2]. Hou X. [4, p. 172] took the education demonstration base of Tianjin Ziya CE industrial zone as an example, analyzed the favorable 
conditions and main ways of establishing the education demonstration base of CE, as well as the restrictive factors in practice, and put forward feasible suggestions for Tianjin to develop CE education.

Zhang Y. et al. [5, p. 174] argued that public participation in CE education is the most effective and economic method in CE implementation, and proposed the path selection of public participation in $\mathrm{CE}$ education from the government, enterprises, communities, schools and non-governmental organization level. As a driver to accelerate the implementation of $\mathrm{CE}$ model, universities have great educational potential for $\mathrm{CE}$ education and can provide reliable support for the popularization of $\mathrm{CE}$ education in the whole society. This paper exposes the contributions that universities can make in CE education.

In order to identify the university educational activities of CE, thereby figure out the educational potential of universities in the implementation of $\mathrm{CE}$, the analysis of recent research and publications was conducted. As the engine of knowledge and technology, the dominant role of universities in carrying out education for sustainable development has been widely recognized. The research of international scholars on the role of higher education institutions mainly focuses on the curriculum setting and the improvement of teaching strategy. Andrews D. [6, p. 305] agued the knowledge and ability to apply the principles of the CE must be embedded in the curriculum so that they also become integral to design practice. In his opinion, not all students will embrace design for sustainable development but it is no doubt that teaching them about the CE will enable sustainability issues to be addressed implicitly. Leubea M. and Walcherb D. [7, p. 492] argued that circular product design is the key problem to make that shift towards the CE, and appealed to renew the Curricula of Design Schools. Fonseca L. et al. [8, p. 1075] used a systematic review utilizing a structured approach to analyze Portuguese higher education institutions BSc and MSc courses and the content analysis of their curricular units, and found that sustainability is covered in most Social Sciences, Engineering, and Management, BSc and MSc courses, offered by the top 8 Portuguese Higher Education Institutions, but the Education for Sustainable Development was lacking a consistent body of knowledge. Hall N. and Colby F. [9, p. 11] argued that a CE approach to curriculum design can motivate deep learning, through experimental practice, deep-dive research and systems thinking, 
and provided a structural framework of a $\mathrm{CE}$ agenda to fashion education curriculum, establishing a novel approach that could be applied to other specialist fashion education institutions. Andara A. et al. [10, p. 414] carried out a survey on a sample of 189 students to test the current sustainability literacy, and created four annual pathways along the roadmap to develop sustainability skills during the four-year college course in engineering, which includes promotion of a recycling campaign through a $\mathrm{CE}$, creation of educational videos regarding sustainability, reinforcement of reasoning and argumentative skills by preparing a debate on environmental issues, and preparation of the students to apply environmental management models to solve sustainability issues within the company. Kopnina H. [11, p. 613] presented a literature review that describes the application of circular methodologies to education for sustainability, which has been slow to adopt circular systems to the curriculum, and discussed how Bachelor and Master level students apply their understanding of these frameworks to corporate case studies. Nunes B. et al. [12, p. 2719] reviewed the environmental activities of 50 universities ranked highly in terms of their environmental credentials or their environmental science courses, and then presented how universities can affect material flows, promote sustainability outside of the formal curriculum, and act as catalysts with business.

In addition, the role of the logistics staff in implementing the education for sustainable development with extra-curriculum activities has attracted the attention of some researchers. Fiselier E. et al. [13, p. 394] presented evidence from an online questionnaire survey and in-depth semi-structured interviews and found that the main challenge HEIs face is engaging staff that may question the relevance of the ESD concept, and that lack an understanding regarding its implications for their discipline, while the critical success factors identified are institution-wide people support, high-level institutional support, and funding. Slobbé C. et al. [14, p. 191] conducted a card-sorting activity among 36 foodservice staff to identify the dominant perspectives held by them about the desirability and realities of fostering environmental education in their workplaces, and argued that buy-in from foodservice staff in university is critical for realizing the potential to foster environmental education in a non-classroom setting and so could have the power to benefit communities through producing environmentally literate graduates. 
In China, the existing researches also focus on the issues that how colleges and universities should carry out sustainable development education through discipline construction and curriculum reform. With the promulgation and implementation of "CE Promotion Law" in China, the development of China's higher education is faced the legal environment of CE. The development strategy of higher education can fully exert the strength of higher education and make the biggest contribution in promoting national economic and social development only if it is a strategy that serves the country's economic and social development. Cui $\mathrm{X}$. et al. [15, p. 13] investigated the current situation and development advantages of Resource Recycling Science and Engineering (RRSE) major in university, and explored the necessity, training objectives and construction modes of this major. Liu X. et al. [16, p. 6] constructed the curriculum system aiming at talent cultivation through the investigation and research on the talent demand of local economic construction and the talent cultivation program of the RRSE major in various universities. Xue J. et al. [17, p. 52] summarized the problems encountered in the teaching process of the professional elective course Clean Production and Circular Economy, and proposed countermeasures to improve the teaching quality from the aspects of textbook construction, case base construction and diversified teaching methods. Gong J. et al. [18, p. 57] highlighted that higher education development strategy should be adjusted in terms of the $\mathrm{CE}$ concept, implement the human resources strategy of $\mathrm{CE}$, enforce the discipline construction and general education of CE, and build a CE culture on campus to realize the scientific development of higher education. Yao W. $[2$, p. 20] argued that universities should advocate CE as an elective course, so as to enable students to participate in CE activities at the ideological, behavioral and practical levels. Xue J. et al. [19, p. 52] found that there are some barriers in teaching process in the universities which have already offered courses related to cleaner production and CE, such as lack of suitable teaching materials and teaching effect is unsatisfactory, and put forward countermeasures to improve teaching quality in light of teaching material construction, case base construction and diversified teaching methods.

Through the literature review of existing research and publications, it is found that the previous research on the education for sustainable development of higher education institutions focused on curricular and extra-curricular 
activities and the research on other pro-circular activities of education potential in universities and is limitation. Systematic analysis of the potential of UCEE has not been carried out. In order to bridge this gap, this study clarifies the subjects and objects in promoting UCEE in terms of theory and practice, and puts forward a systematic strategy to improve the UCEE.

\section{Subjects and objects of UCCE}

Before studying the UCEE, the subjects and objects of UCEE should be made clear firstly. In general, the main subject of university education is the educator, that is, the teacher, and the object is the educated, that is, the student. CE is an economy that developed in a knowledge-based society. The concept of CE needs the understanding, support, participation and practice of the whole society. Therefore, CE education is the national, lifelong, participatory ability education [2, p. 19]. As one of the main driving forces of promoting CE model, the universities are not only the promoters of CE education at the whole society level, but also the cultivators of professional talents, the creators of advanced CE technology, and the pioneers and demonstrators of CE practice. Consequently, the subjects and objects of UCEE are more complicated. The main subjects of UCEE is not limited to teachers, but should be extended to all staff who practice CE in universities and the graduates with knowledge and consciousness of CE who entered the society. These two groups are very large, but both of them are easily overlooked resources in higher education compared with teachers, that can be seen in Figure 1. Owing to the implementation of CE depends on the whole society receiving good education and deep understanding of CE concept, the objects of UCEE is no longer limited to college students, but the whole public. Also, the participants of UCEE should also include some relevant departments of colleges and universities, such as the $\mathrm{CE}$ policy making and planning department and the curriculum management department.

Through the analysis of existing research, it can be seen that the main subjects in universities to implement $\mathrm{CE}$ education include the direct subjects (the CE policy making and planning department, the curriculum management department, teaching faculties and student social practice department) and indirect subjects (professional teachers with CE knowledge, the logistics staff with CE concept and the students with CE knowledge), 
Dongxu Qu, Tetiana Shevchenko

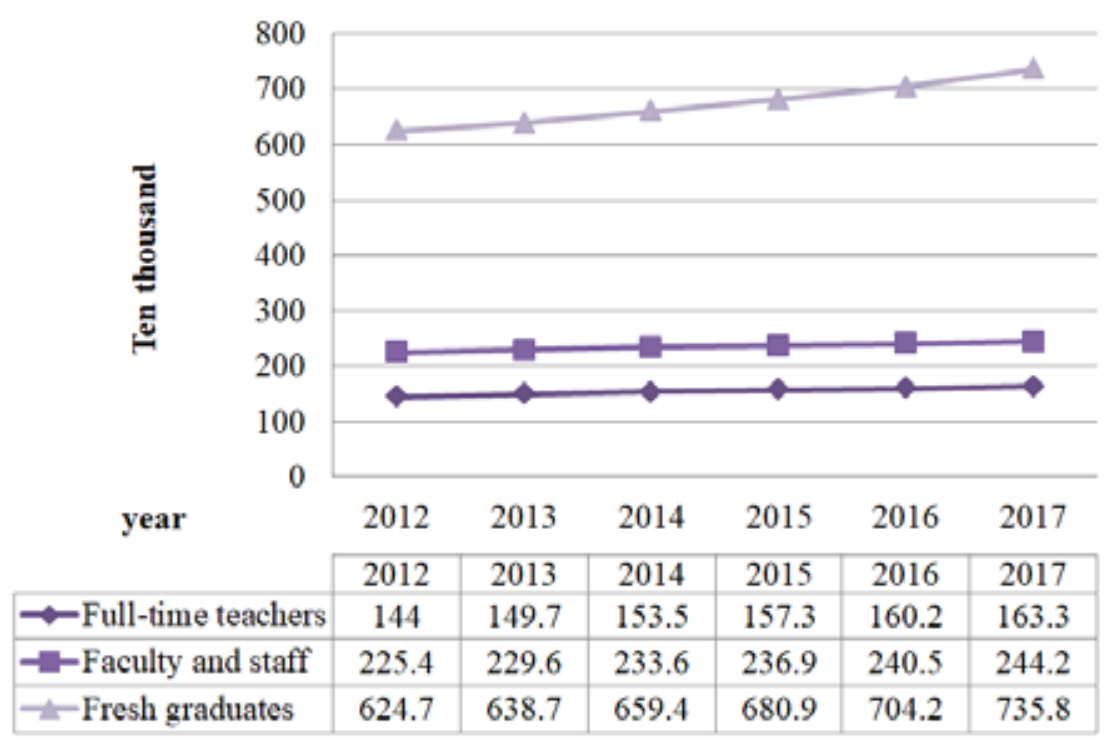

Figure 1. Number of relevant personnel in Chinese colleges and universities (2012-2017)

while the objects of $\mathrm{CE}$ education of universities mainly include students, residents of surrounding communities and the public, as shown in Figure 2.

In addition, the target of UCEE is not limited to the stage education of cultivating high-level professionals, but to the lifelong education of cultivating the whole social group as much as possible into citizens with CE concept and knowledge. As for the educational mode, UCEE should not only carry out theoretical education, but also carry out participatory practical education. Theoretical knowledge and intelligence should be put into innovative activities, and their ability should be properly displayed in CE practice, so as to meet the needs of CE implementation.

Based on the above concepts, the definition of UCEE can be put forward for the first time. University circular economy education is a novel theoretical definition, which refers to a lifelong education with the guidance and support of relevant management departments of the universities, and the participation of all teachers and staff. It radiates education to the whole society with the education of college students as the core, aiming at realizing 


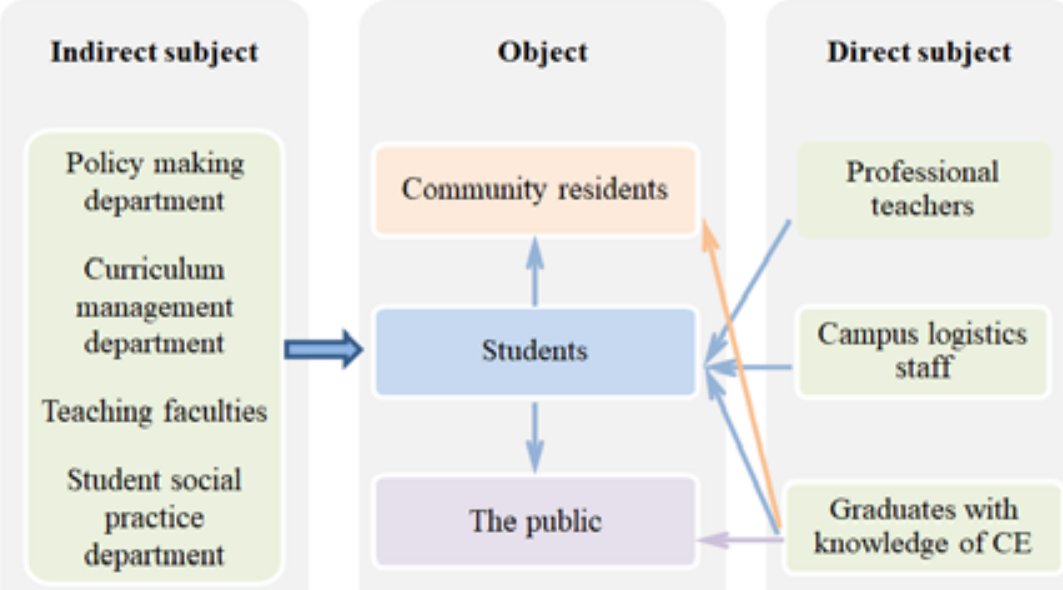

Figure 2. Subjects and objects in implementing UCEE

the two primary targets of cultivating high-level professional talents of CE and enhancing the awareness of $\mathrm{CE}$ of the whole public.

\section{Barriers in promoting UCEE}

There are also some barriers in carrying out UCEE. First of all, the policy support for the CE practice in universities is insufficient. At present, Chinese college administrators have a single orientation on logistics departments, mainly requiring them to do well in various aspects of logistics support work, and indirectly serve the teaching and research of universities. In fact, the logistics departments of the university have good conditions for the implementation of CE, such as the implementation of canteen waste recovery project. Meanwhile, logistics work is closely related to students' life, which has the direct advantage of developing CE education for students. Through the investigation of all 134 colleges and universities of Henan province in China, it is found that, up to now, no college or university has made relevant policies to combine departments and related CE majors to play their direct educational functions, or provided policy support for departments to directly participate in CE education. Secondly, the CE 
concept and cognition are insufficient, and the general education needs to be strengthened. On the one hand, some leaders and teachers of applicationoriented colleges and universities think that general education is of limited practical significance, and they tend to focus on professional skills, and are unwilling to put general education in the same important position as professional education. Its essence is still the insufficient understanding of general education, or the supremacy of utilitarianism. On the other hand, some students pay little attention to general education. Due to the fierce competition in the current society, students always have a strong sense of pragmatism and attach more importance to professional courses. The general education class is treated worthlessly by the students because of the failure to recognize the importance of general education for personal growth and social development. Thirdly, the professional development is relatively lagging behind. Since 1995 and 1996 the Ministry of Education established the major of Renewable Resources Science and Technology in colleges and universities, more than ten colleges and universities have applied for the specialty successively. In 2010, the Ministry of Education established the undergraduate major of RRSE in order to meet the needs of China's economic and social development, and renamed the original major of Renewable Resource Science and Technology as RRSE in 2012 [16, p. 9]. Compared with developed countries, China's recycling economy started relatively late, and the development of RRSE is also relatively backward. China's Statistical Yearbook 2018 that released by the National Bureau of Statistics shows that, up to 2019, only 46 col-leges and universities in China have offered offers the major of RRSE [20]. Statistics from the Ministry of Education show that among all the provinces in China, Beijing, Liaoning and Shandong have the largest number of universities that offering Resources Recycling Science and Engineering major, as shown in the Fig.3. There are also eight provinces that do not offer the major in any colleges and universities. Fourthly, the professional curriculum construction needs to be strengthened. The curriculum system construction overwhelmingly emphasizes the impartation of theoretical knowledge, while the curriculum setting has obvious defects in the cultivation of practical ability and vocational skills. Theoretical teaching is divorced from practical teaching, and the training of theoretical knowledge and practical skills is not coordinated, which leads to the poor practical ability of college students 
after graduation and makes it difficult to meet the needs of enterprises. For this emerging major, the universities that have offered this major are still in the initial exploration stage in terms of its construction ideas and curriculum system setting [15, p. 13]. The training scale is small, the talent training program and teaching material construction are not perfect, which greatly restricts the development of this major.

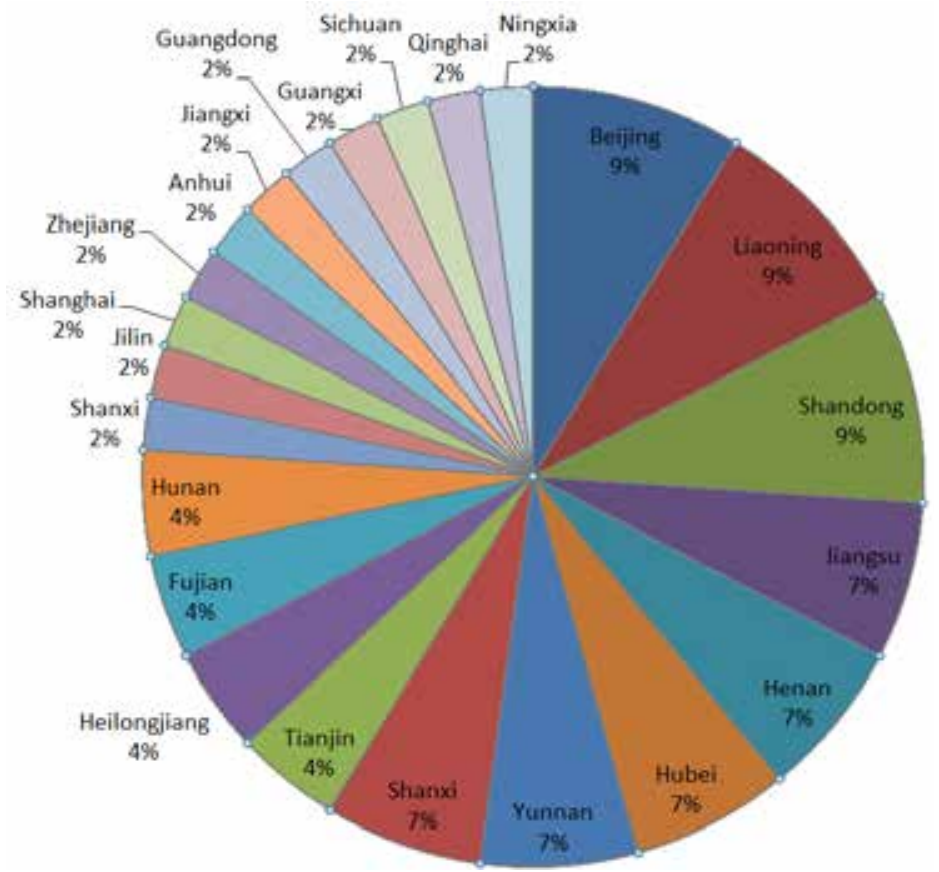

Figure 3. Distribution of colleges and universities offering RRSE major in provinces in China

Finally, the CE education radiation of the extracurricular activities of student associations and the social practice activities to the public are not enough. At present, many universities have set up Environmental Protection Associations to spread the concept or knowledge of CE among students. The students' social practice department in universities also regularly organizes students to participate in environmental protection training and 
competition based on their major, which to some extent makes up for the students' lack of knowledge in this field. However, there are still few procircular activities between colleges and communities, and the effect of the $\mathrm{CE}$ educational radiation from universities to the whole society is still not significant.

\section{Education potential of university to implement $\mathbf{C E}$}

The CE education for students is embodied in the general $\mathrm{CE}$ education for all students and the cultivation of professional talents. Also, the CE education for the residents of the surrounding communities and the public is embodied in the use of educational resources of universities to radiate the $\mathrm{CE}$ education to the whole society in varying degrees. Therefore, the education potential of universities to implement the CE model is mainly reflected in the following aspects.

In terms of policy formulation, the premise for universities to exploit the advantages of CE education is the policy support. With the support of relevant policies, universities can carry out lots of $\mathrm{CE}$ practices, which will become an important way for universities to conduct $\mathrm{CE}$ education and publicize the CE concept. Actually, many foreign universities have started different practices of CE. In China, although the role of universities in promoting the transformation to $\mathrm{CE}$ model has been widely recognized, and the work of energy conservation and environmental protection in universities is evaluated by higher education authorities every year, similar practices are still rare in Chinese colleges and universities. If universities integrate the $\mathrm{CE}$ into their development programs and formulate relevant development policies, the logistics department can combine the advantages of the university to actively explore the CE practice in various fields of the university. Pilot projects in universities could be arisen to catalyze the CE practice by working with business to improve eco-effectiveness as well as eco-efficiency. For example, universities can establish campus domestic garbage sorting system, reclaimed water circulation system, shared cycling system, learning resources recycling system and canteen waste recovery systems. Whether the water recycling or food recycling on campus, these are kinds of hidden extra-curricular education in daily life. Moreover, logistics staff with $\mathrm{CE}$ concept can play an active role in the process of non-classroom environmental education, and its influence on students' 
pro-circular behaviors can be as effective as formal $\mathrm{CE}$ education. The implementation of extracurricular education of $\mathrm{CE}$ in universities relied on the $\mathrm{CE}$ practice on campus and the logistics staffs, as shown in Figure 4.

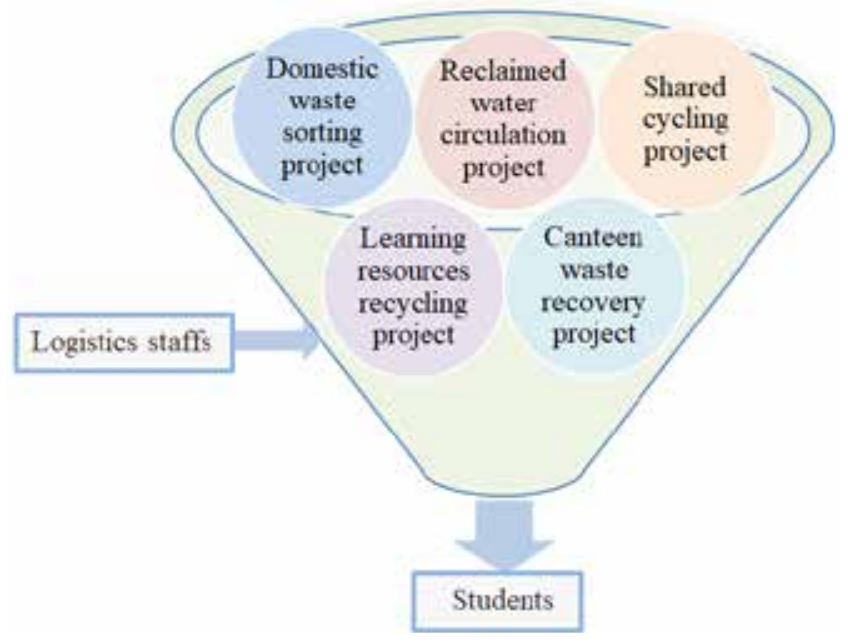

Figure 4. Implementation of extracurricular education of $\mathrm{CE}$ for students

In terms of the general education, the curriculum management department or general education center of universities should strengthen the overall arrangement of general education in CE. The CE implementation requires the participation of the public with the awareness of CE. University students are a huge group, and the data from the National Bureau of Statistics of China shows that the number of university graduates in China has exceeded 7 million every year since 2013 [20]. Also, as the backbone force of various industries in the future, the undergraduate with $\mathrm{CE}$ knowledge could become the practitioner and disseminators of the $\mathrm{CE}$ concept to improve the $\mathrm{CE}$ awareness in the whole society. Moreover, college students can also achieve CE education through peer learning. Therefore, it is of great significance to classify CE knowledge as the content of general education among all majors in universities. The overall arrangement 
of general education in universities should include the arrangement of teachers and curriculum demonstration. The first is to raise awareness of the importance of general education of CE. Under normal circumstances, general education cannot gain obvious results in a short period of time, and it is difficult to get the attention of leaders, teachers and students in many universities. The second is to establish the $\mathrm{CE}$ teacher reserve to ensure the CE teaching needs. Currently, there is a shortage of teachers in the field of CE. While cultivating relevant teachers, universities should also improve the integration of teachers in the region. General education of $\mathrm{CE}$ should be carried out by combining professional and part-time teachers and adopting online and offline teaching. The third is to set up the general education curriculum of CE strictly and scientifically. The applied education is popular in China. So, there are many problems in application-oriented universities, such as the general courses are fewer than professional courses, choices for students are insufficient, and general courses and professional courses are mutual separated from each other. In order to achieve the goal of general education of CE, universities should strengthen the scientific demonstration of the courses, reasonably setting course modules, carefully arranging course contents, scientifically organizing and implementing course teaching, and integrating general education and professional education with each other [21, p. 101].

In terms of the professional personnel training, the relevant teaching faculties and departments should strengthen the cultivation of professional talents according to the needs of the society for CE professionals. The cultivation of professional talents of $\mathrm{CE}$ is the guarantee for the implementation of CE and CE industry. Facing the severe employment situation, it is very important to cultivate talents who meet the needs of social development. The "Higher Education Law" in China expressly pointed out that the three major functions of Chinese universities are teaching, scientific research and social service. The function orientation of universities determines that it is the statutory duty of universities to cultivate urgently needed talents for economic construction. At present, talents in the field of CE are in short supply. However, the majors related to $\mathrm{CE}$ are emerging majors and the development is still in the initial stage, there is still a long way to progress. The development of these majors should take the social demand as the purpose, take the cultivation of 
compound talents as the guidance, strengthen the construction of the teaching staff, and set out the professional construction road with its own characteristics. Therefore, professional colleges and universities that have not yet established the major of CE should apply for establishing the $\mathrm{CE}$ major and implement the strategy of strengthening the country with human resources. In addition, the curriculum system of CE major should be optimized to meet the needs of CE education. Educational administrative departments shall carry out planned and organized research on the construction of specialized disciplines of $\mathrm{CE}$ in institutions of higher learning, formulate scientific and reasonable training programs, and establish the guarantee system of talent training in the field of CE. Besides, the construction of professional laboratory and CE practice base between universities and enterprise should be strengthened. As a more intuitive and vivid form, the practice and application of CE model is an effective way in CE education [22, p. 148].

In terms of educational radiation to society, the student social practice de-partment and propaganda department of universities should improve the cooperation with surrounding communities and other relevant institutions in the society. With the educational resources, universities can integrate $\mathrm{CE}$ knowledge and concepts into social practice, spread the pro-circular value to surrounding communities and the public, and guide residents to form green consumption habits. For example, Japan is a country suffered from heavy environmental disasters, so they build a large number of environmental education sites with excellent practical functions, aiming to promote the public awareness of the environment and form spontaneous pro-environment behaviors [23, p. 36]. In China with the educational resources and the platform of student social practice, universities can use for reference of the successful experience of environmental education venues in Japan to set up CE education venues in conjunction with the community to provide visiting and explanation services for community residents and primary and secondary school students, and collect volunteers to carry out online and offline publicity and education in various forms. By adopting flexible and intuitive ways, public participation can be enhanced. Also, the effect of CE education can be improved by continuous improvement of educational methods through obtaining feedback. 


\section{Conclusions}

In general, it is widely accepted that moving from a linear model of production and consumption to a $\mathrm{CE}$ model is a better choice, which can minimize environmental pollution and resource consumption, and reposition the economic system to improve competitiveness. However, $\mathrm{CE}$ education is an important guarantee to put $\mathrm{CE}$ into practice. As one of the important subjects to implement $\mathrm{CE}$ education, universities should stimulate their educational potential in implementing the transition to $\mathrm{CE}$ model. All of the department in universities which can make contribution to $\mathrm{CE}$ education should be involved, including the policy making and planning department, the curriculum management department, teaching faculties, student social practice department and propaganda department. Also, all the professional teachers, the logistics staff with CE concept and the students with CE knowledge should be engaged in the CE education by paying attention to the general education of $\mathrm{CE}$ for all the students, cultivating professional talents of $\mathrm{CE}$ to meet the needs of the social, and radiating $\mathrm{CE}$ education from the universities to the surrounding community residents and the public.

From the process of analyzing the educational potential of universities, it can be seen that the main way for universities to implement $\mathrm{CE}$ education is that the university first carry out $\mathrm{CE}$ education for students in various ways, and then the students with CE knowledge spread the $\mathrm{CE}$ concept to the public in different ways. That is, students will play a key role in the process of CE education that universities implemented. Therefore, the situation of college students' pro-circular awareness and pro-circular behavior should be paid attention to in the future research. In addition, the pilot project of $\mathrm{CE}$ should be actively carried out in all fields of colleges and universities. Also, it is necessary to strengthen the discipline construction of the majors related to $\mathrm{CE}$ and curriculum setting. After that, the effective way to evaluate the effect of all kinds of $\mathrm{CE}$ education methods should be explored to find the advantages and problems in practice, so that find out the advantages and problems of various education methods, and solve the obstacles in a targeted way, so as to ensure the effectiveness of CE education in colleges and universities, and really promote the transformation of $\mathrm{CE}$ model in the whole society. 


\section{References:}

1. Gong J. (2010). On the role of higher education in developing circular economy. Journal of Jiangxi Finance College, 23(5): 132-134.

2. Yao W. (2006). Analysis of China's circular economy education. Technology Economics, 2: 19-20.

3. General office of the national development and reform commission (2013). Notice on issuing special funds for circular economy development to support the implementation plan of national circular economy education demonstration base construction. Renewable Resources and Circular Economy, 6(5): 1-2.

4. Hou X. (2017). Restriction and guarantee of circular economy education a case study of Tianjin Ziya circular economy industrial zone. China Journal of Commerce, 10: 172-174.

5. Zhang Y., Jiao S., \& Wang S. (2014). The path selection of public participation in circular economy education in China. Productivity Research, 4: 100-104.

6. Andrews D. (2015). The Circular economy, design thinking and education for sustainability. Local Economy, 30(3): 305-315.

7. Leube M., \& Walcher D. (2017). Designing for the next circular economy: an appeal to renew the curricula of design schools. The Design Journal, 20(1): 492-501.

8. Fonseca L., Portela A., Duarte B., Queirós J., \& Paiva L. (2018). Mapping higher education for sustainable development in Portugal. Management \& Marketing, 13(3): 1064-1075.

9. Hall N., \& Colby F. (2018). AMFI's reality school: a circular economy agenda for fashion education. Art, Design \& Communication in Higher Education, 17(1): 11-24(14).

10. Andara A., Belver R., Salvador M., \& Nicolás R. (2018). Roadmapping towards sustainability proficiency in engineering education. International Journal of Sustainability in Higher Education, 19(2): 413-438.

11. Kopnina H. (2019). Green-washing or best case practices? Using circular economy and cradle to cradle case studies in business education. Journal of Cleaner Production, 219: 613-621.

12. Nunes B., Pollard S., Burgess P., Ellis G., Rios I., \& Charnley F. (2018). University contributions to the circular economy: professing the hidden curriculum. Sustainability, 10(8): 2719.

13. Fiselier E., Longhurst J., \& Gough G. (2018). Exploring the current position of ESD in UK higher education institutions. International Journal of Sustainability in Higher Education, 19(2): 393-412.

14. Slobbé C., Mirosa M., \& Thomson C. (2017). University foodservices' potential for providing environmental education to students. Nutrition \& Dietetics, 74(2): 191-199.

15. Cui X., Di Y., Zhou C., Liu X., Nan N., \& Xu S. (2018). Training mode of applied talents in RRSE from the perspective of circular economy. Renewable Resources and Circular Economy, 1: 12-15.

16. Liu X., Li R., Zhou C., \& Cui X. (2017). Construction of curriculum system of Resource Recycling Science and Engineering major serving local economic construction. Renewable Resources and Recycling Economy, 10(12): 6-9. 
17. Xue J., Hu S., Gao Y., Li L., \& Zhang W. (2018). Problems and countermeasures in the teaching of clean production and circular economy. China Metallurgical Education, 6: 52-54.

18. Gong J., Wei Q., Miao N., \& Xin L. (2010). The development strategy selection of higher education under the legal background of circular economy. Journal of Educational Academic, 1: 56-57.

19. Xue J., Hu S., Gao Y., Li L., \& Zhang W. (2018). Problems and countermeasures in the teaching of clean production and circular economy. China Metallurgical Education, 6: 52-54.

20. The national bureau of statistics of China. China statistical yearbook 2018. Available at: http://www.stats.gov.cn/tjsj/ndsj/2018/indexeh.htm

21. Li L., \& Gao J. (2019). The concept and practice of general education in application-oriented universities. China Three Gorges Tribune, 3: 101-104.

22. Yue W. (2013). Practice and application of school-enterprise practice education base in circular economy - a case study of faculty of chemistry and chemical engineering in Xuzhou University of Engineering. Industrial and Science Tribune, 12(24): 148-149.

23. Lin Y., \& Shi G. (2013). How to operate and manage environmental education venues in Japan. Environmental Education, 10: 36-41. 